\title{
Performance Analysis of Improved Vehicle Muffler
}

\author{
Tie WANG, Jinrui GAO, Yushuai BU \\ School of Automobile and Transportation, Shenyang Ligong University, Shenyang 110159, China, \\ E-mail: wangtiesylg@163.com \\ cross $^{\text {ref }}$ http://dx.doi.org/10.5755/j01.mech.24.5.17784
}

\section{Introduction}

The research of muffler is complex because it is associated with more disciplines such as acoustics, aerodynamics, fuel economy, heat transfer and so on. Amit Kumar Gupta introduced the measurement of acoustic transmission loss about a single-chamber muffler with different ratios of length to diameter [1]. MA Habib et al. have controlled the backpressure to a suitable range by means of an automated mechanical IRIS. The mechanical IRIS provides a variable outlet diameter for the exhaust muffler based on engine speed, which in turn controls back pressure and improves vehicle fuel economy [2]. S Banerjee et al. analyzed the sound attenuation in SIDO and DISO circular chamber mufflers by a general procedure based on three dimensional Green's function [3]. Denia used a three-dimensional analytical method to analyze the acoustic performance of a reflow-type muffler [4]. Vijayasree et al. analyzed the transmission loss of a complex multi-cavity muffler based on the global transfer matrix method and proposed a generalized one-dimensional Method [5]. Hua and Herrin used the dualload method to obtain the transmission loss of the muffler [6]. Adrien Mann et al. used the LBM solver (PowerFlow) to evaluate the geometric self-induced noise of the muffler baseline, to understand the noise generation mechanism, and to propose a design approach to noise reduction [7]. Renato Barbieri et al. studied the numerical calculation of muffler transmission losses by using acoustic/passive finite element analysis of the acoustic chamber and GA (Genetic Algorithm) optimization with integer variables [8]. Jang and Lee optimized the import and export of expansion mufflers by applying acoustic and flow topology optimization methods [9].

Through the domestic and international research overview, the different research methods and performance improvement measures of muffler are discussed. In view of the merits of reactive muffler and resistance muffler, the combination of resistance and reactive structures to improve the muffler performance are mainly studies in this paper.

\section{The relevant model and performance analysis}

\subsection{Bounding parameter of muffler}

In this paper, the muffler structures need to be improved and the performances of muffler improved need to be evaluate through the relevant indicators. It is necessary that the exhaust gas parameters are used as boundary conditions and the steady-state engine condition are selected for numerical calculation and analysis. GT-POWER used by all major engine manufacturers is the industry standard engine performance simulation software, it includes various physical engine models, now we choose a four cylinder 2.0 litre atmospheric gasoline engine (a mainstream car engine model in the world that muffler inlet exhaust speed is about $63 \mathrm{~m} / \mathrm{s}$ when the engine speed is $4500 \mathrm{r} / \mathrm{min}$ ). In order to analyze physical pheomena, the gas temperature of inlet is regarded as $873 \mathrm{k}$, the corresponding physical parameters are shown in Table 1.

To the hydrodynamic performance analysis, standard k-epsilon turbulence model is set, that can uniform inlet flow rate, regardless of gravity, pulse and other effects; the wall boundary conditions are set to adiabatic, smooth and non-slip. To the Turbulence option, we select the high turbulence density. The outlet of the muffler is arranged in the form of a pressure outlet, the relative pressure of outlet is set to 0pa, because the muffler is installed in the exhaust system end, that the outlet is directly connected with the atmosphere.

Related gas physical parameters [10]

\begin{tabular}{|c|c|c|c|c|}
\hline Temperature & Density $\rho(\mathrm{kgm}-3)$ & $\begin{array}{c}\text { Thermal conductivity } \\
\lambda(\mathrm{wm}-1 \mathrm{~K}-1)\end{array}$ & $\begin{array}{c}\text { Specific heat capacity } \\
c p(\mathrm{Jkg}-1 \mathrm{~K}-1)\end{array}$ & $\begin{array}{c}\text { dynamic viscosity } \\
\mu(\mathrm{kgm}-1 \mathrm{~s}-1)\end{array}$ \\
\hline $873 \mathrm{~K}$ & 0.404 & $6.222 \times 10-2$ & 1089 & $3.91 \times 10-5$ \\
\hline
\end{tabular}

\subsection{Establishment and analysis of original muffler model}

\subsubsection{Establishment of model based on GT-POWER}

The original muffler studied in this paper is a purely reactive muffler, its spindle cross section is oval, the diameters of intubation, inlet and outlet all are $50 \mathrm{~mm}$, the major axis of the cross-section ellipse is $220 \mathrm{~mm}$ and the minor axis is $150 \mathrm{~mm}$. The total length of the original muffler is $570 \mathrm{~mm}$, the muffler body is divided into three chambers that the lengths of the first, second and third chambers are $155 \mathrm{~mm}, 140 \mathrm{~mm}$ and $125 \mathrm{~mm}$ respectively. The portion of the inlet tube in the first chamber has small holes with diameter $6 \mathrm{~mm}$ and about $15 \%$ perforation rate [11]. The GEM3D module of GT-POWER software is used to build the muffler model that can be discretized and imported into GT-POWER for acoustic analysis. The hydrodynamic analysis of the muffler is carried out in the fluid software ANSYS CFX. The overall size of the muffler is large with small local structure, such as small holes, etc., so it is important that the appropriate size of the grid should be se- 
lected. Because the smallest hole diameter of original muffler is $6 \mathrm{~mm}$, the hexahedral three-dimensional grid with $4 \mathrm{~mm}$ length is mainly selected. The original muffler $3 \mathrm{D}$ model is shown in Fig. 1.

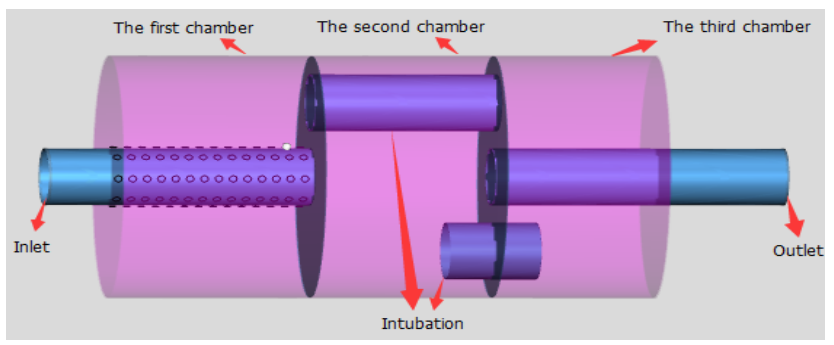

Fig. 1 The original muffler 3D model

\subsubsection{Performance analysis of original muffler}

After the relevant parameters are set, the original one-dimensional model of the muffler is imported into GTPOWER, and the acoustic performance analysis is carried out. The fluid domain grid model is imported into ANSYS CFX for fluid analysis.

Through the analysis of the different performance of the muffler, the original muffler acoustic performance is shown in Fig. 2.

It can be seen that the velocity of airflow about the original muffler intubation is large (The velocity of airflow increases rapidly and reaches the maximum speed $105 \mathrm{~m} / \mathrm{s}$ ), which is mainly due to the change of the cross-sectional area of the pipe. In the first chamber, the intake pipe forms a large static pressure, results in increased exhaust back pressure and the highest pressure reaches $5400 \mathrm{~Pa}$. The pressure loss is the average total pressure difference between inlet and

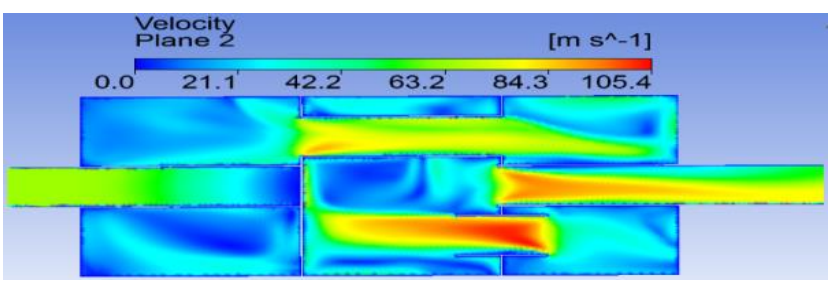

a

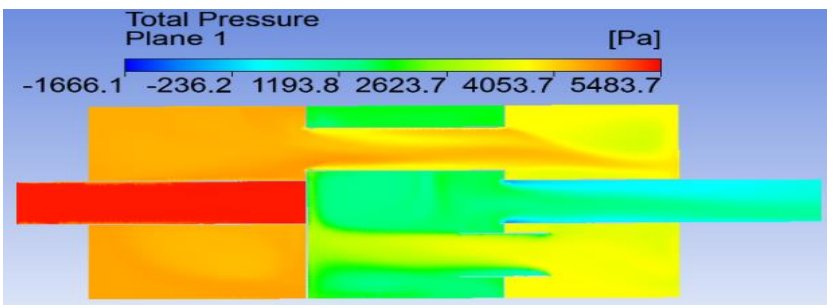

$\mathrm{c}$

Fig. 3 The hydrodynamic performance of original muffler (a) Velocity cloud, (b) Velocity vector, (c) Total pressure cloud, (d) Turbulence kinetic energy

\subsection{Improvement and analysis of muffler}

\subsubsection{Improvement of muffler}

To the improvement of muffler, acoustic performance is mainly to improve transmission loss and aerodynamic performance is mainly to reduce back pressure, that outlet, and this original muffler pressure loss is about $4.20 \mathrm{kPa}$.

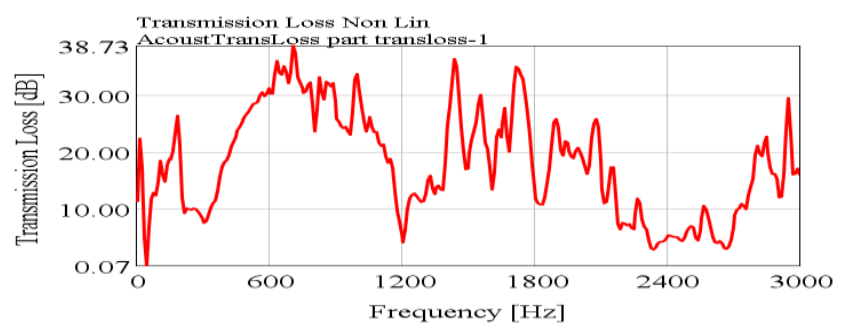

a

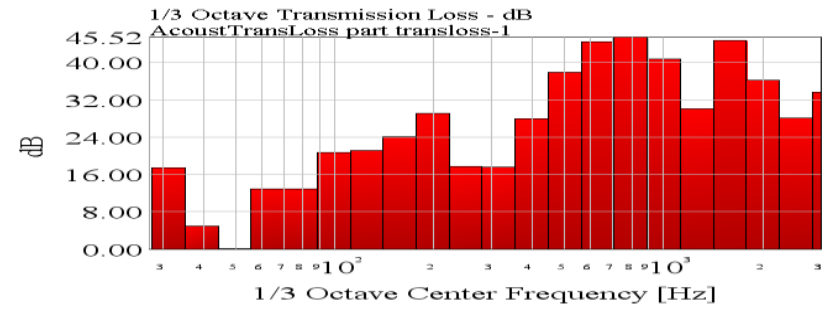

b

Fig. 2 The acoustic performance of original muffler (a) transmission loss, (b) 1/3 Octave transmission loss

It can be seen that an octave band of $1200 \mathrm{~Hz}$ has good elimination effect, the sound volume of $500 \sim 1000 \mathrm{~Hz}$ frequency range is about $25 \sim 35 \mathrm{~dB}$. With the increase of frequency, there are many peaks in the $1800 \sim 2200 \mathrm{~Hz}$ frequency range, but the overall muffler's capacity of noise elimination is decreasing, especially in the high-frequency range.

The hydrodynamic performance of the muffler is carried out in the fluid software ANSYS CFX, and the result is shown in Fig. 3.

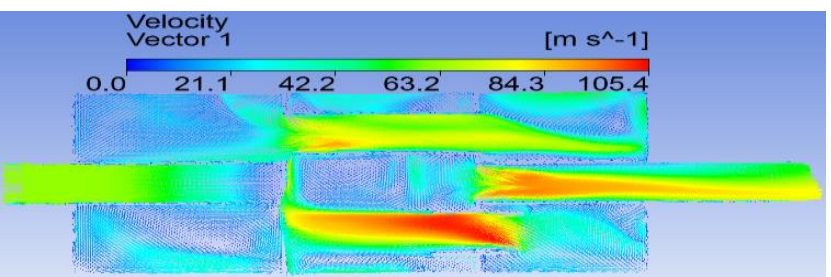

b

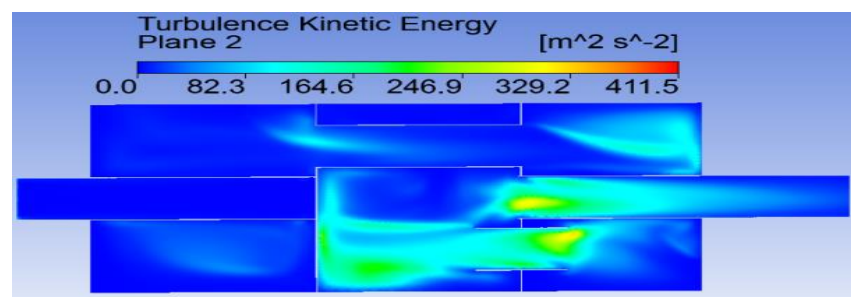

d

can reduce the engine power loss and ensure fuel economy. It is important to choose the proper structure and to make the main parameters (such as length of inlet and outlet pipe of muffler [12]), when the noise attenuation is large and the power loss is small. In view that the reactive muffler in the high-frequency effect is poor, and dissipative muffler in the high frequency effect is very good, we use impedance com- 
posite design to improve the overall muffler effect. To improvement process of muffle, we generally observe following requirements: a) ensure the engine and car performance; b) installation position, external shape, volume, inlet and outlet diameter of muffle remain basically unchanged for interchangeability, so inner construction changes are mainly considered. To satisfy above requirements, we design and validate many solutions, finally, we get the following two best schemes.

Option one: Muffler shape and volume remain unchanged and the diameter of the inlet is still $50 \mathrm{~mm}$. A shroud is installed in the perforated portion of the inlet pipe. The reactive silencer material is added between the pipe and the shroud. The second and third cavities are separated by a perforated baffle that the holes of diameter $6 \mathrm{~mm}$ are evenly distributed on the baffle. The diameter of the U-shaped tube and the outlet tube is set to $40 \mathrm{~mm}$ for increase the expansion ratio. The inlet of the U-shaped tube is in the second chamber and is a quarter of the length of the second chamber, when the outlet of the U-shaped is in the first chamber and the length is one-half the length of the first chamber. The length of the outlet tube in the chamber is one fourth of the length of the first chamber. In this way, the complex structure is formed by the combination of pipes and the abrupt change of cross-section, so that the sound waves are cancelled each other by the reflection effect [13]. The muffler $3 \mathrm{D}$ model of scheme 1 is shown in Figure 4.

Option two: while muffler total length and volume remain unchanged, the three chamber structure is changed into four chambers. The lengths of the first chamber to the fourth chamber are 130, 105, 120 and $65 \mathrm{~mm}$. The first and third chamber are the dilatation chambers, the second and fourth chambers are the resonant chambers. The diameter of inlet and the long intubation are changed to $45 \mathrm{~mm}$, and the long intubation located the second chamber has small holes with diameter $6 \mathrm{~mm}$. The tip of the long intubation is inserted at 1/4 length of the third chamber, the end of the longer tube is inserted $1 / 2$ at length of the first chamber, the front end of the exhaust tube is inserted 1/4 at length of the first chamber. The muffler 3D model of scheme 2 is shown in Fig. 5.

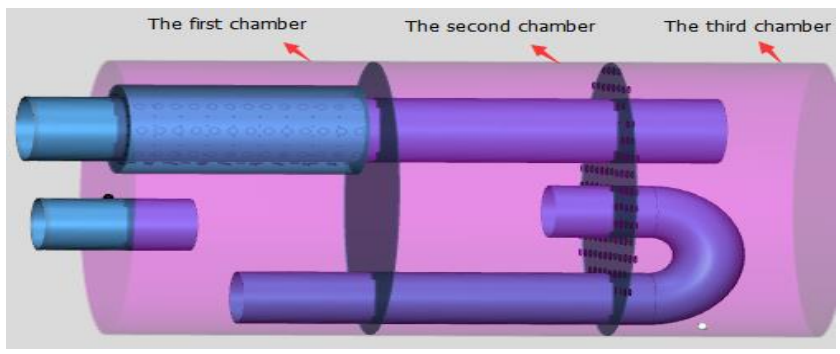

Fig. 4 The muffler 3D model of scheme 1

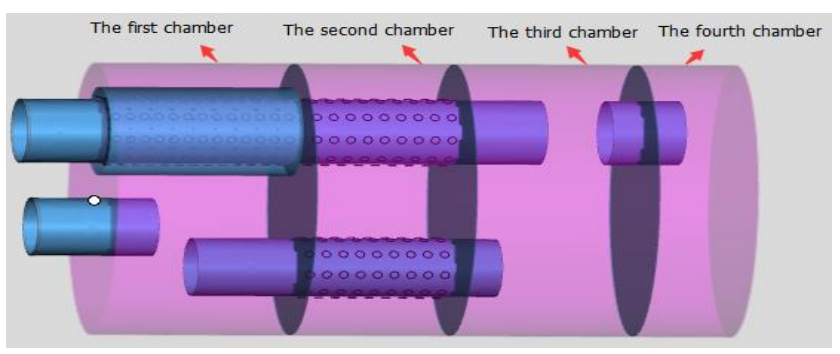

Fig. 5 The muffler 3D model of scheme 2

\subsubsection{Analysis of improved muffler}

To the simulation analysis, the parameters and boundary conditions of the two schemes are the same as original muffler. The acoustic performance comparison between the original and the scheme 1 muffler are shown in Figure 6 as simulation results, where Fig. 6, a is transmission loss and Fig. 6, b is 1/3 Octave transmission loss.

It can be seen that the scheme 1 muffler characteristics have great changes. In the frequency range of $0 \sim 3000 \mathrm{~Hz}$, the scheme 1 muffler's capacity of noise elimination is improved, especially in the high-frequency section, is nearly three times as much as original. In the low frequency range of $200 \sim 400 \mathrm{~Hz}$, the average noise elimination result is increased about $23 \mathrm{~dB}$, and in the $1800 \sim 2800 \mathrm{~Hz}$ frequency band, result is almost all over $40 \mathrm{~dB}$.

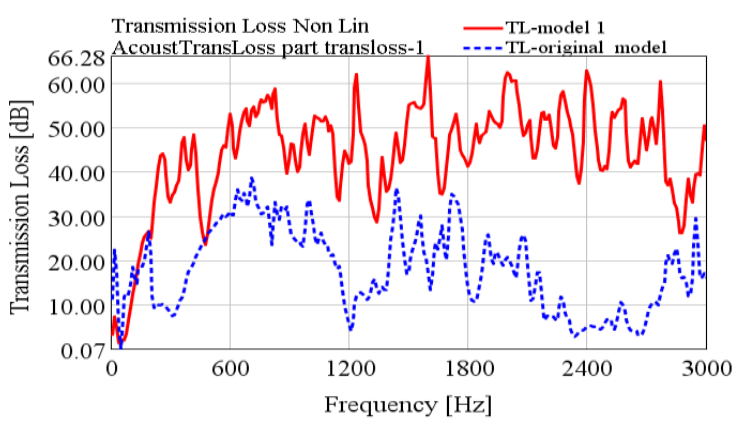

a

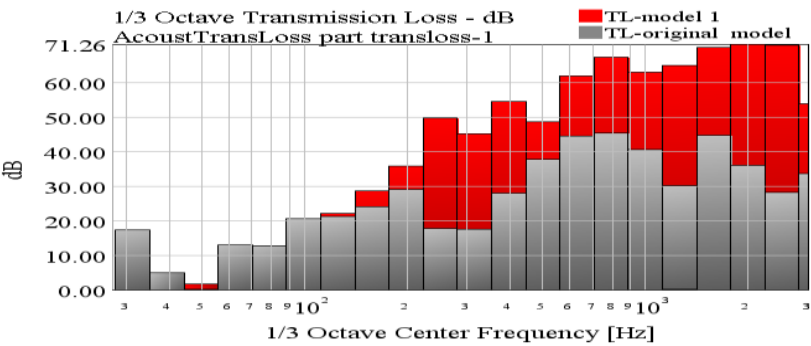

$\mathrm{b}$

Fig. 6 The acoustic performance comparison between the original and the scheme 1 (a) transmission loss (b) $1 / 3$ Octave transmission loss

The hydrodynamic performance of scheme 1 muffler is shown in Fig. 7.

In terms of hydrodynamic performance, the pressure in the muffler inlet pipe is the largest, reaching $11,000 \mathrm{~Pa}$. The pressure loss is the average total pressure difference between inlet and outlet, and the scheme 1 muffler pressure loss is about $8.06 \mathrm{Kpa}$. The acoustic performance comparison between the original and the scheme 2 muffler are shown in Fig. 8 as simulation results, where Fig. 8, a is transmission loss and Fig. 8, b is $1 / 3$ Octave transmission loss. As can be seen from Fig. 8, in the frequency range of $1000 \sim 3000 \mathrm{~Hz}$, the scheme 2 muffler's capacity of noise elimination is improved, especially in the high-frequency section of $1800 \sim 3000 \mathrm{~Hz}$, the capacity of noise elimination is improved significantly. In the frequency range of $2100 \sim 2600 \mathrm{~Hz}$, the average noise elimination result is increased nearly $35 \sim 40 \mathrm{~dB}$.

The hydrodynamic performance of the scheme 2 muffler are shown in Fig. 9. 


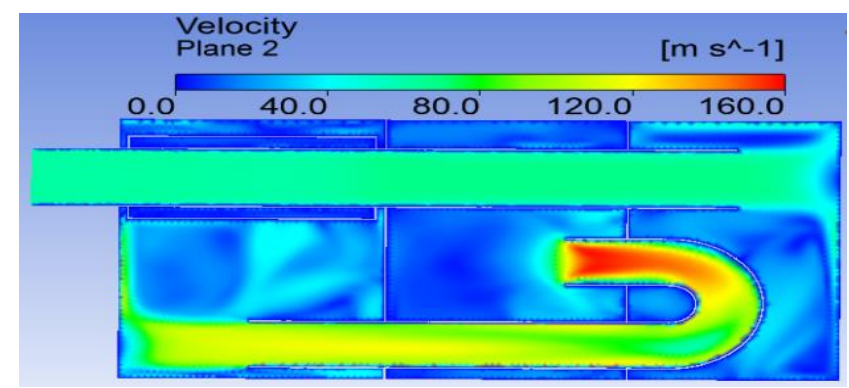

a

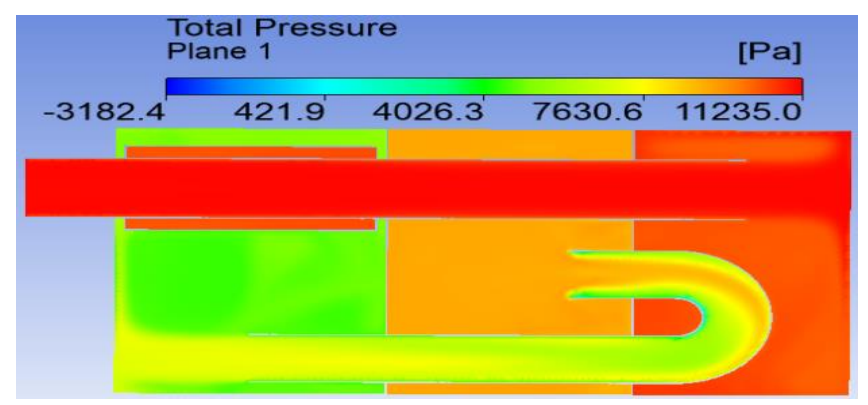

$\mathrm{c}$

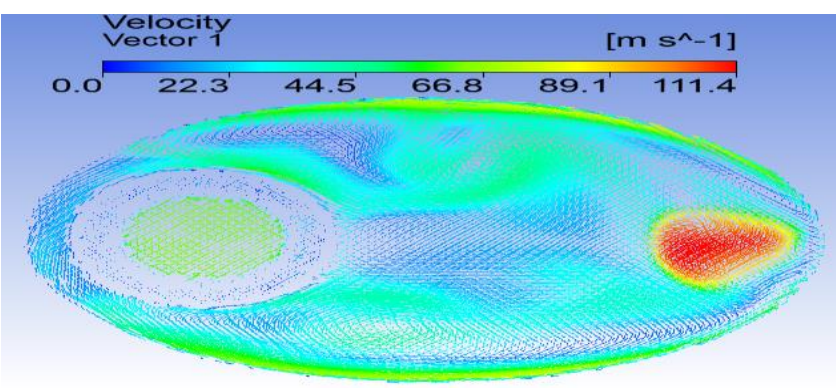

e

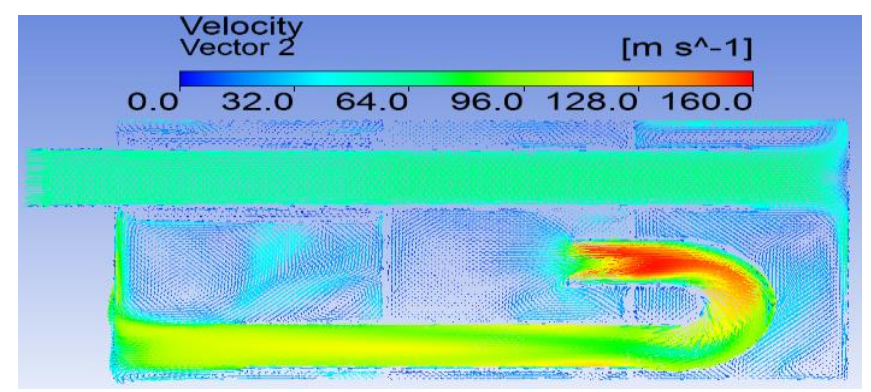

b

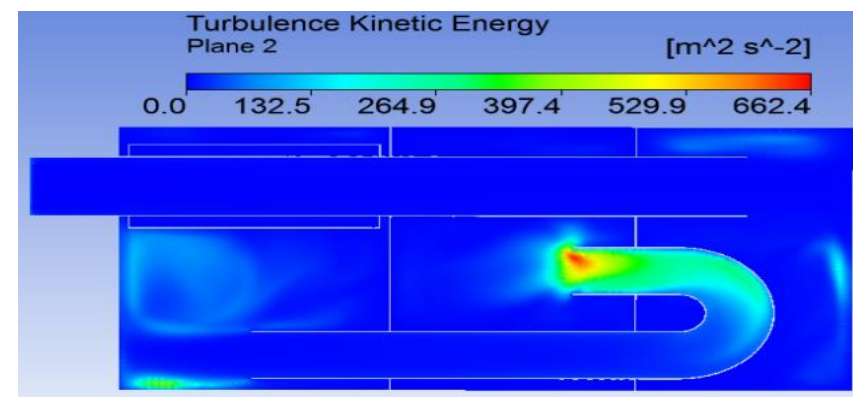

d

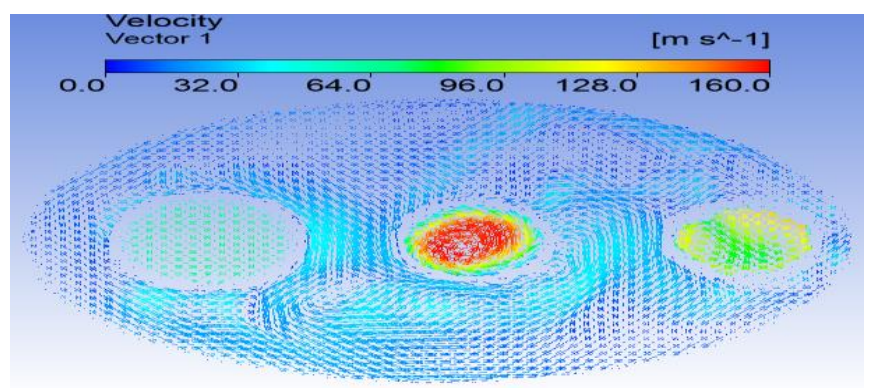

$\mathrm{f}$

Fig. 7 The hydrodynamic performance of scheme 1 muffler (a) Velocity cloud, (b) Velocity vector, (c) Total pressure cloud, (d) Turbulence kinetic energy, (e) Velocity vector diagram of the first chamber, (f) Velocity vector diagram of the second chamber

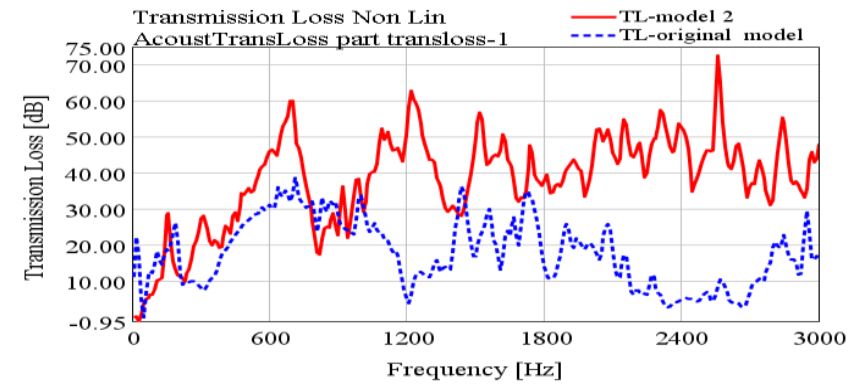

a

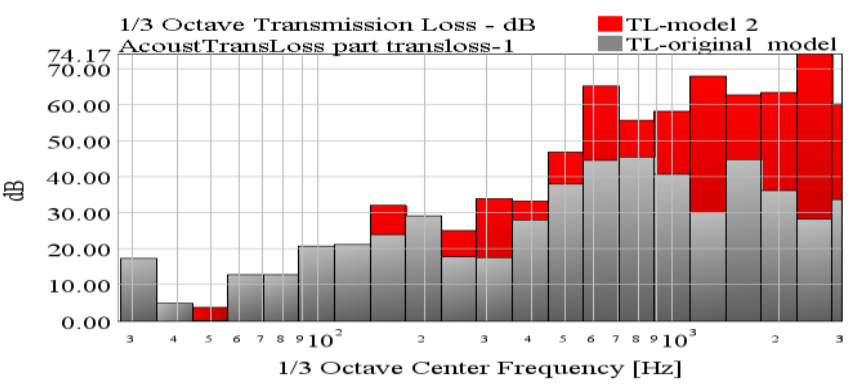

b

Fig. 8 The acoustic performance comparison between the original and the scheme 2 (a) transmission loss (b) 1/3 Octave transmission loss

From Fig. 9, a, it can be seen that the airflow from the third chamber to the first chamber through the intubation increases sharply, the maximum speed has reached $120 \mathrm{~m} / \mathrm{s}$, this is due to a sudden decrease in the cross-sectional area of the gas flow path and leading to a rapid increase in the gas flow rate. In Fig. 9, b, the pressure from the first chamber to the fourth chamber is gradually increasing, because the air flow has great speed and make high dynamic pressure. The scheme 2 muffler pressure loss is about $3.3 \mathrm{kPa}$.
In acoustic performance, two improved mufflers have been greatly improved, especially in the high frequency band. The Scheme 1 muffler's capacity of noise elimination on different frequency bands are very good, and the improvement is particularly evident. The improvement effect of scheme 2 muffler is not great in the middle and low frequency band, especially in the low frequency. In the hydrodynamic performance, the small pressure loss is beneficial to exhaust and improve fuel economy, the pressure loss of the scheme 1 muffler is bigger than the original one and the scheme 2 is smaller than the original one. 


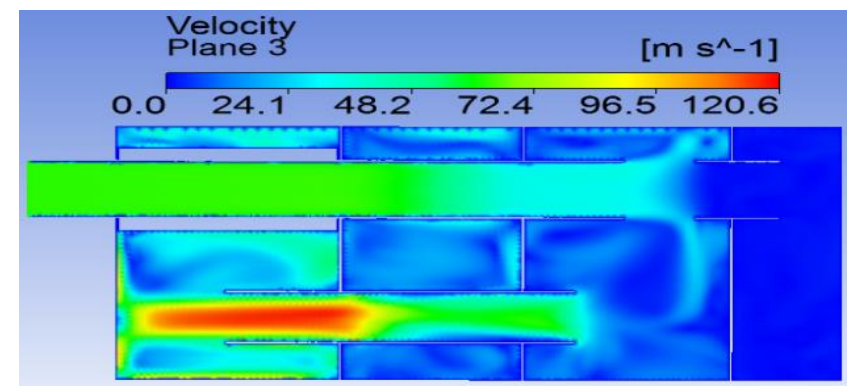

a

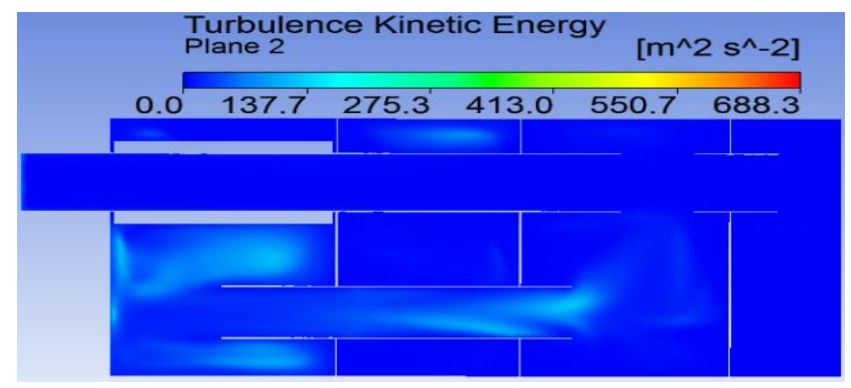

c

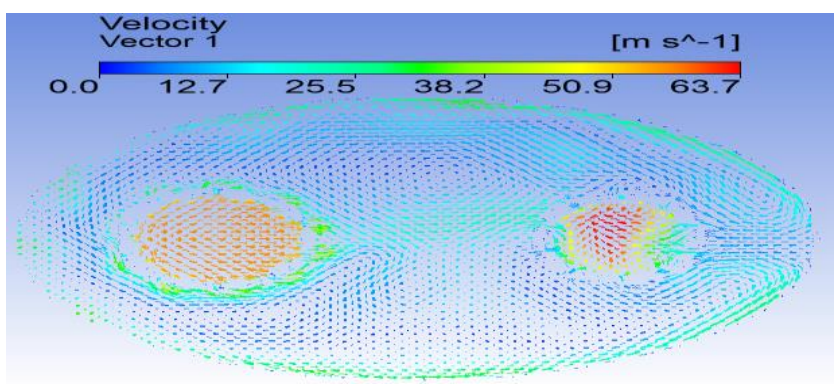

e

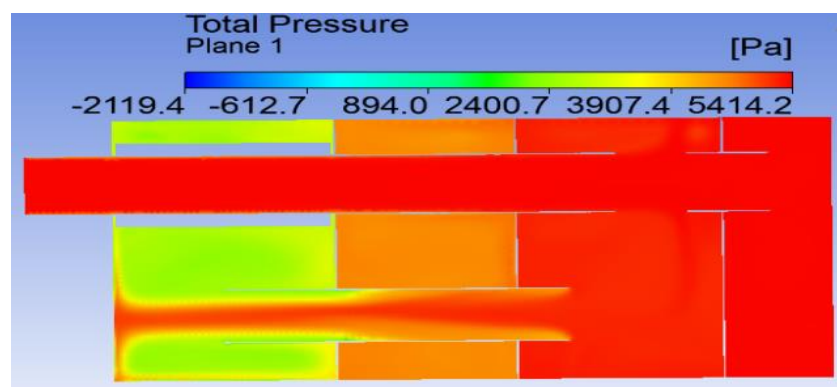

b

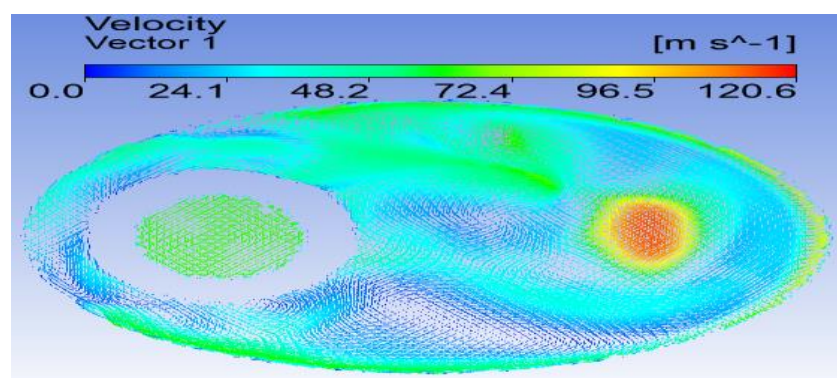

d

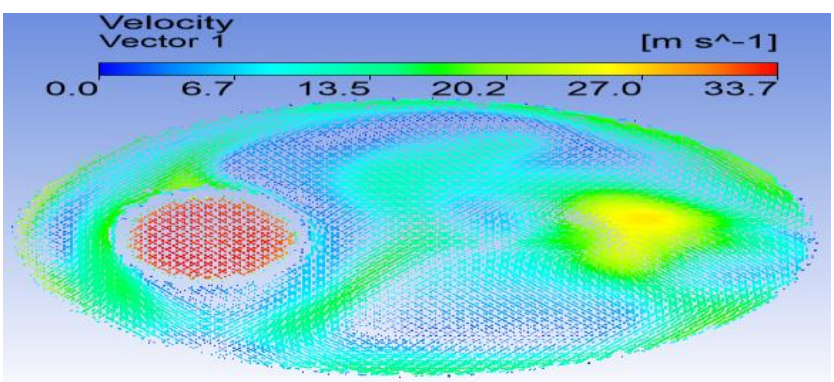

f

Fig. 9 The hydrodynamic performance of scheme 2 muffler (a) Velocity cloud, (b) Total pressure cloud, (c) Turbulence kinetic energy, (d) Velocity vector diagram of the first chamber, (e) Velocity vector diagram of the second chamber, (f) Velocity vector diagram of the third chamber

\section{Conclusion}

1. For analyzing the acoustic performance of muffler, this paper builds the muffler transmission loss model. For analyzing hydrodynamic performance of muffler, this paper obtains the velocity and temperature of tail gas at the muffler inlet under the standard working condition through engine simulation model.

2. This paper finds that, the noise elimination effect of original muffler in low frequency performs well, especially in the frequency range below $1200 \mathrm{~Hz}$. With the increase of frequency, there are many peaks in the $1800 \sim 2200 \mathrm{~Hz}$ frequency band, but the noise elimination effect of original muffler decreased, especially in the high-frequency range.

3. This paper finds that, when the gas flows in the muffler, the turbulence will be formed due to the blockage of the wall surface and the change of the airflow direction. The combination of different muffler units and the change of the cross section of the chamber will also affect the air flow.

4. The results show that the improved scheme is feasible to enhance the performance of muffler and noise elimination effect of impedance muffler in high frequency is better than reactive muffler. It also shows that muffler performance can be improved by the combination of different muffling units and the rational arrangement of the length of the pipe.

5. Following the improvement of the muffler, the overall structures of the muffler become complicated, following the improvement of acoustic performance, the pressure loss often can have increased. It also shows that the number change of insertion tubes and cavities will have a certain influence on the pressure loss of the muffler.

\section{References}

1. Gupta, A. K. 2016. Transmission loss of cylindrical muffler with different length to diameter ratio by using two load method and simulation tool, International Journal of Engineering Sciences and Management Research 3(4):27-32. https://doi.org/10.5281/zenodo.50165.

2. Habib, M. A.; Anwar, A. S.; Patwari, M. A. U. 2016. An innovative concept to improve the muffler performance using automated mechanical IRIS, Journal of Engineering and Applied Sciences 11(2):1035-1039.

3. Banerjee, S.; Jacobi, A. M. 2013. Transmission loss analysis of single-inlet/double-outlet (SIDO) and double-inlet/single-outlet (DISO) circular chamber mufflers by using Green's function method, Applied Acoustics 74(12):1499-1510. 
https://doi.org/10.1016/j.apacoust.2013.06.007.

4. Denia, F. D.; Antebas, A. G.; Selamet, A.; Pedrosa, A. M. 2011. Acoustic characteristics of circular dissipative reversing chamber mufflers, Noise Control Engineering Journal 59(3): 234-246. https://doi.org/10.3397/1.3560904.

5. Vijayasree, N. K.; Munjal, M. L. 2012. On an integrated transfer matrix method for multiply connected mufflers, Journal of Sound and Vibration 331(8):19261938. https://doi.org/10.1016/j.jsv.2011.12.003.

6. Hua, X.; Herrin, D. W. 2013. Practical considerations when using the two-load method to determine the transmission loss of mufflers and silencers, SAE International 6(2):1094-1101.

https://doi.org/10.4271/2013-01-1881.

7. Mann, A.; Min, S. K.; Neuhierl, B. et al. 2015. Exhaust and muffler aeroacoustics predictions using lattice boltzmann method, SAE International Journal of Passenger Cars 8(3):1009-1017. https://doi.org/10.4271/2015-01-2314.

8. Barbieri, R.; Barbieri, N. 2012. The technique of active/inactive finite elements for the analysis and optimization of acoustical chambers, Applied Acoustics 73(2):184-189. https://doi.org/10.1016/j.apacoust.2011.08.002.

9. Jang, G. W.; Lee, J. W. 2015. Optimal partition layout of expansion chamber muffler with offset inlet/outlet, International Journal of Automotive Technology 16(5):885-893. https://doi.org/10.1007/s12239-015-0090-6.

10. DOC88.com. The physical properties of dry air [EB/OL]. (2014-07-04) [2016-12-01]. http://www.doc88.com/p-2488175943586.html.

11. Miao, K. H. 2015. The numerical simulation analysis on acoustic and fluid dynamic performance of exhaust Muffler based on FLUENT. Xi an : Changan university.

12. Chaitanya, P.; Munjal, M. L. 2011. Effect of wall thickness on the end corrections of the extended inlet and outlet of a double-tuned expansion chamber, Applied Acoustics 72(1):65-70.

https://doi.org/10.1016/j.apacoust.2010.09.001.

13. Ghazikhani, M.; Hatami, M.; Ganji, D. D., et al. 2014. Exergy recovery from the exhaust cooling in a DI diesel engine for BSFC reduction purposes, Energy 65(1):4451. https://doi.org/10.1016/j.energy.2013.12.004.

Tie Wang, Jinrui Gao, Yushuai Bu

\section{PERFORMANCE ANALYSIS OF IMPROVED VEHICLE MUFFLER}

S u m m a r y

In this paper, the engine model is built and the boundary parameters of specified conditions are gotten by using GT-POWER software. The acoustic performance and fluid dynamics are analyzed by means of GT-POWER software and CFX module of ANSYS software. The original muffler is evaluated by searching the transmission loss and pressure loss. Based on the simulation results and muffler theory, the relevant parameters and layout of the original muffler structure are improved. Two different improved schemes are put forward, through the obtained acoustic data and the hydrodynamic performance diagram, the mufflers of two schemes are evaluated respectively. The results show that the improved schemes are feasible to enhance the performance of muffler and noise elimination effects in high frequency performs are well.

Keywords: muffler; GT-POWER; CFX; peformance analysis; improved.

Received March 17, 2017

Accepted October 18, 2018 